\title{
Distribution of Shallow Isochronous Layers in East Antarctica Inferred from Frequency-Modulated Continuous-Wave (FMCW) Radar
}

\author{
Wangxiao Yang ${ }^{1}$, Yinke Dou*,1, Shinan Lang ${ }^{2}$, Jingxue Guo ${ }^{3}$, Guangyu Zuo ${ }^{1}$, \\ Yan Chen ${ }^{1}$, Yuchen Wang ${ }^{1}$ \\ (1) Taiyuan Univ Technol, Coll Elect \& Power Engn, Taiyuan 030024, China \\ (2) Beijing Univ Technol, Sch Informat \& Commun Engn, Beijing 100124, China \\ (3) Polar Res Inst China, Shanghai 200136, China
}

Article history: received June 2, 2018; accepted July 22, 2019

\begin{abstract}
During the $32^{\text {nd }}$ Chinese National Antarctic Research Expedition, the Frequency-Modulated Continuous-Wave (FMCW) radar was used for the first time to obtain the distribution of shallow isochronous layers within the East Antarctic region extending from Zhongshan Station to Kunlun Station. Taking a typical area as a case study, this article describes the complete workflow used in radar data processing, including signal processing and extraction of isochronous layers. The wave velocity model is established according to an empirical formula to calculate the depth of the layer, and the result is compared and corrected with the volcanic record in ice core DT263; the relative error of depth is only approximately $5 \%$. The echograms of the isochronous layers in three regions are presented, including the area around the Dome A, the area $100 \mathrm{~km}$ from the Dome A and the area in the Lambert Glacier. A comparison of the echograms within the three regions shows that the isochronous layers are relatively stable in the Dome A and change more intensely in the Lambert Glacier, while the folding of the layer occurs in a concentrated area near Dome A. This folding may be due to the local layer mixing and compression caused by the ice flow and wind-driven processes. The analysis of the distribution of the shallow isochronous layers and age-depth information from different regions provides important data that support the calculation of large-scale accumulation rates and flow history in the Antarctic.
\end{abstract}

Keywords: Frequency Modulated Continuous Wave (FMCW) radar; Shallow isochronous layer; Horizon data extraction; Distribution characteristics; Horizon fluctuation.

\section{Introduction}

The density of ice formed in different periods differs within glaciers [Paren and Robin, 1975], and the different characteristics caused by variations in density or conductivity, as well as variations in crystal orientation fabric 


\section{Wangxiao Yang et al.}

(COF), can result in the detection of distinct layers (isochronous layers) from electromagnetic-wave reflection signals [Paren and Robin, 1975; Siegert, 1999; Fujita et al., 1999; Vaughan et al., 1999]. Based on this feature, various radar systems (e.g. AWI, BAS, CRe-SIS, INGV and UTIG) have been developed for the study of Antarctic ice sheets [Winter et al., 2017]. Most radar systems can provide reliable detection at depths of several kilometers [Drewry, 1975; Macheret and Zhuravlev, 1982]. Radio-echo sounding (RES) is widely used to detect the thickness of the Antarctic ice sheet, the presence of subglacial lakes and the distributions of ice and bedrock [Gogineni et al., 1998].

The Prydz Bay-Amery Ice Shelf-Dome A Project Expedition and Research Plan is an important program of the Chinese Antarctic expedition, and completed continuous observations of multiple parameters from Prydz Bay near Zhongshan Station to the highest point on Dome A (Figure 1) [Mayewski et al., 2005; Xiao et al., 2013; Gui et al., 2007]. Along this profile, ice sounding radar was used to determine several large-scale glacial parameters (e.g., ice thickness and ice distribution) in the area of interest. The West Antarctic Ice Sheet (WAIS) Divide deep ice core project has also mapped the deep internal layers in West Antarctica [Laird et al., 2010]. However, the ability of ice sounding radar to detect the internal features of the top ice sheet is limited, making it difficult to observe the distribution of isochronous layers in shallow ice sheets (within the $200 \mathrm{~m}$ ) [Conway et al., 2005]. Instead, highresolution ice sounding radar can be used to detect features within the shallow glacier. Le Meur et al. [2018] used ground-penetrating radar to detect the East Antarctic Plateau and obtained continuous isochronous layers spatial distributions within $\sim 100 \mathrm{~m}$ of depth between Dome Concordia (DC) and Vostok Station.

To determine the continuous isochronous features of a shallow ice sheet over longer distances, and to add the available data on East Antarctic ice sheet dynamics and surface mass balance (SMB) [Gogineni et al., 2007], the inland Kunlun team of the 32nd Chinese National Antarctic Research Expedition (CHINARE 32) used FMCW sounding radar to fully observe the ice sheet along a route extending from the inland base ( $8 \mathrm{~km}$ from Zhongshan Station at the margin of the ice sheet) to Kunlun Station near Dome A (Figure 1), and obtained echograms of shallow isochronous layers in the East Antarctic with a total distance of $1280 \mathrm{~km}$ from the coast to the inland. These data are of great value for analysis the temporal and spatial variability of SMB and provide a basis for reconstructing Antarctic climates and deducing the effects of future climate change.

This paper first describes the process of data acquisition and processing during the CHINARE 32 . To better demonstrate the process by which information on the isochronous layers and their depths were extracted, we employed Profile 1, as shown in Figure 1, to illustrate the long-distance profile generation process. We established a velocity model of the electromagnetic waves in the ice sheet and calculated the depth of the layer according to the two-way travel time (TWT). The results were calibrated with reference to the volcanic records of the ice core (code: DT263; GPS coordinates: S76 $32^{\prime} 28^{\prime \prime}$, E77 $01^{\prime} 32^{\prime \prime}$ ) drilled by CHINARE 19 [Cui et al., 2009]. The age-depth information of the layer was calibrated by the ice core [Petit et al., 1981], which can be used for large-area extraction isochronous layers to calculate the accumulation rate. In addition, portions of the Dome A region, a region $100 \mathrm{~km}$ from Dome A, and the Lambert Glacier were selected to map the isochronous layers. These regions are illustrated in Figure 1 as Profiles 2, 3, and 4, respectively. By analyzing the echograms of the long-distance isochronous layers in these regions, they exhibit completely different characteristics, which are closely related to the accumulation rate between regions. The data presented in this paper facilitate calculations of large-scale accumulation rate and can be used to analyze the temporal and spatial distribution of SMB in the $1280 \mathrm{~km}$ range (from Zhongshan Station to Dome A). These data also provide the foundation for reconstructing past climates in the Antarctic and analyzing the flow history.

\section{Materials and methods}

Considering the need for precise detection of shallow isochronous layers and the lack of a large amount of convenient energy, FMCW sounding radar was used in this work.

Compared to sounding radars with a depth of several kilometers, the FMCW sounding radar sweep bandwidth used in this study was $1.5 \mathrm{GHz}$, and the period was $4 \mathrm{~ms}$, resulting in a high vertical resolution of $6.16 \mathrm{~cm}$ in firn/ice. The trace repetition rate was 100 traces/s; each trace contained 24,576 points at a sampling rate of $6.25 \mathrm{MS} / \mathrm{s}$ and was able to measure the isochronal layer within 10-100 m. The system power was $2 \mathrm{~W}$, but due to power limitations, only the rising component of the radar signal was used [Stove, 1992; Leuschen et al., 2014; Urbini et al., 2017]. 


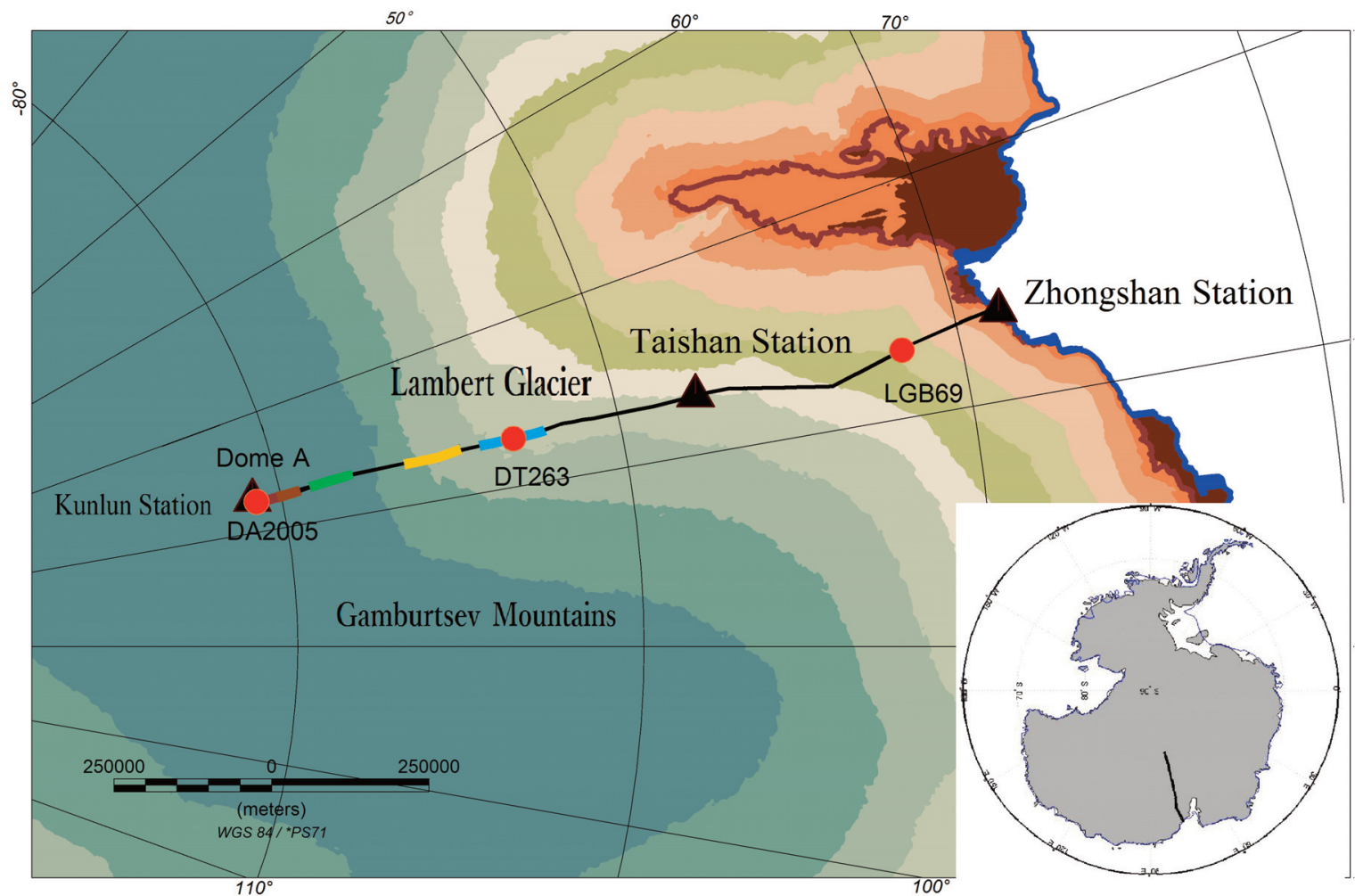

\section{Ice core $\boldsymbol{\Delta}$ Station $\square$ Profile $1 \square$ Profile $2 \square$ Profile $3 \square$ Profile 4}

Figure 1. The location of the radar detection trajectory extending from the base to Kunlun Station. The locations of four typical areas (Profile 1 to Profile 4), an ice core and nearby stations are shown.

The sounding radar system was mounted on the trunk of a PistenBully 300 Polar snowmobile and collected data at a speed of $14 \mathrm{~km} / \mathrm{h}$. The main control box was installed inside the trunk, and the antennas were affixed to the top of the snowmobile; its small size provided portability. The distance between the transmitting and receiving antennas exceeded $2 \mathrm{~m}$ [Galin et al., 2012]. Because a metal rod would interfere with the signal and could cause accidents when violent bumps occur, a bamboo pole was used to secure the antenna (Figure 2). The location of the radar traces was obtained by a high-precision global positioning system (GPS) mounted on other vehicles and was sampled synchronously with the FMCW sounding radar. The inland Kunlun team of CHINARE 32 departed from the inland base on December 15, 2015 and arrived at Kunlun Station on December 30.
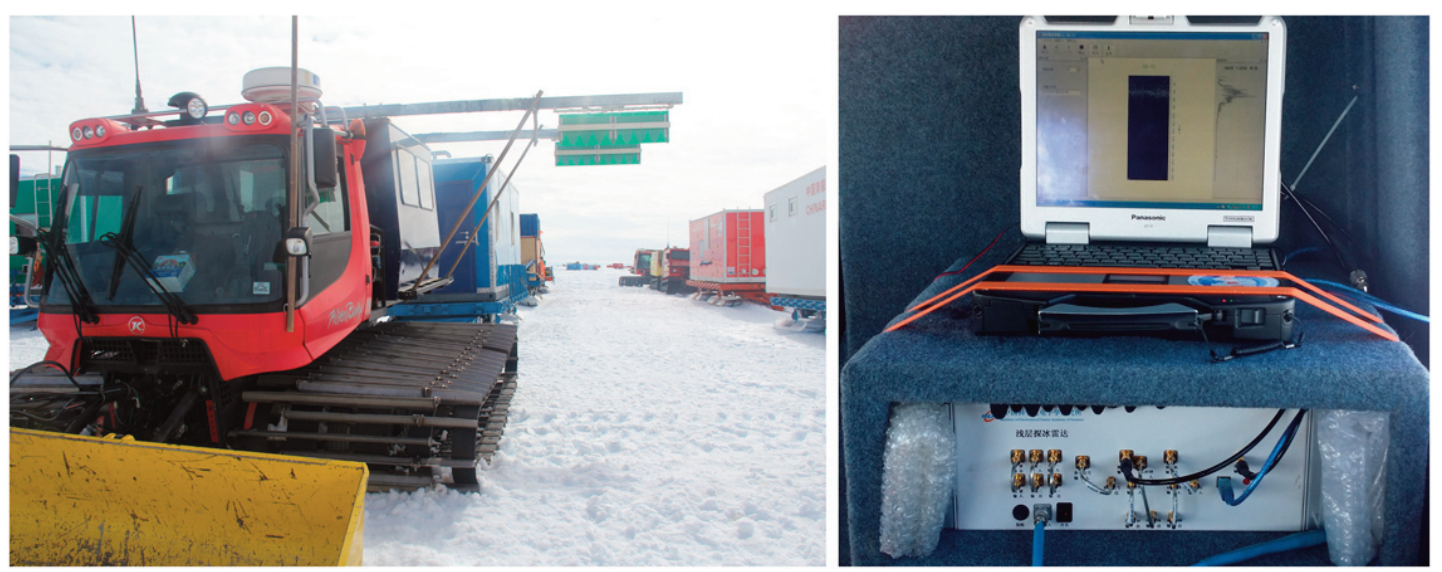

Figure 2. Sounding radar system and antenna arrangements on the snowmobile. 


\section{Wangxiao Yang et al.}

\section{Signal processing}

The main purpose of this stage is to optimize the quality of the data and prepare for the subsequent layer mapping. The specific process is shown in Figure 3.

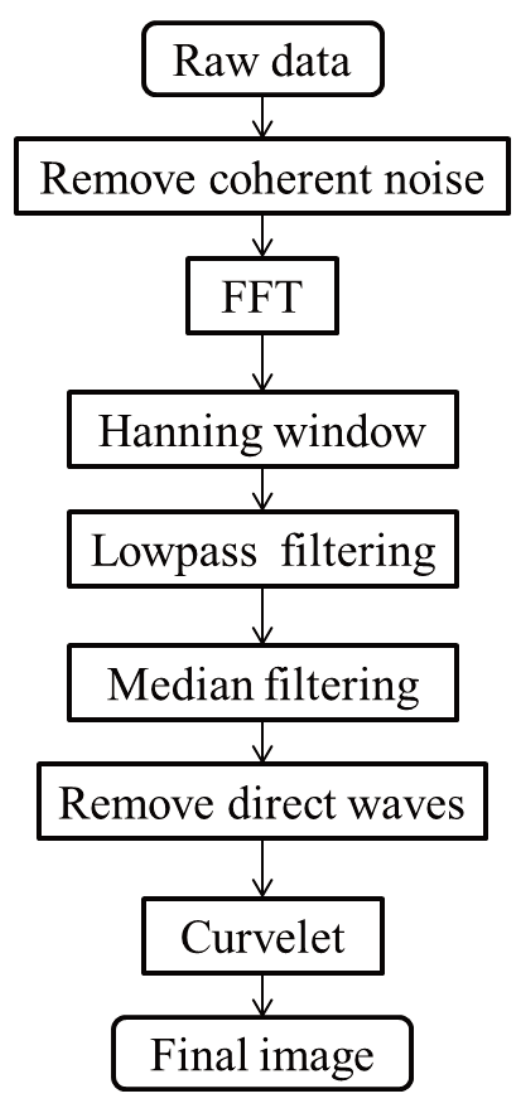

Figure 3. Preprocessing flow chart.

The raw data contain considerable coherent noise when they are collected. This noise will affect the extraction and analysis of ice structure, making the echogram blurry and unable to effectively show the isochronal layer. Taking into account the signal-to-noise ratio, only the last of every 8 traces received by the radar was preserved to suppress coherent noise [Urbini et al., 2010].

The original data were stored in the time domain; a fast Fourier transformation (FFT) was applied to the original data to obtain a spectrum plot, and a Hanning window was applied to the data to reduce the range sidelobes. Because there is a $1 / \mathrm{r}^{2}$ reduction in power with range, we applied a lowpass filter to the spectral data, and a filter with a very low cutoff frequency was used. The original spectra were then multiplied by the inverse of the lowpass filter response to correct for the gain. The median filter approach filters out multiplicative noise and maintains the sharpness and smoothness of the edge regions of the layer [Bakwad et al., 2009].

On the surface of the detection area, the maximum interference in the radar signal is caused by direct waves [Bao et al., 2014]. A direct wave is generated when the transmitting antenna propagates a signal through the wire to the receiving antenna, and electromagnetic waves are reflected when passing through the surface of the ice sheet. According to the FMCW ranging principle (the distance is proportional to the frequency), the frequency of a direct wave is lower than the normal radar reflected signal; a high pass filter was constructed to filter out the direct waves so that the fundamental harmonic of the direct waves was completely filtered.

After the above processing, the curvelet transform must be applied to attenuate background and random noise [Uslu et al., 2014]. According to previous studies [Lang et al., 2015a; Langet al., 2015b], the curvelet transform was established to extract the features of the layer. This step allowed us to effectively distinguish isochronous layers. 
Figure 4 shows that the distribution of the layers is more obvious after this intensive processing. After a clear image was obtained, the distance and depth of this echogram could be calculated. When calculating the distance of the profile, according to the principle of sounding radar and referring to the radar parameters in Section 2, the distance of the profile can be accurately calculated from the number of traces $\mathrm{N}$ :

$$
S=v^{*} T_{s w p} * N
$$

where $v$ is the horizontal movement speed of the sounding radar; a snowmobile can carry the radar at a constant speed of $14 \mathrm{~km} / \mathrm{h} . T_{\text {swp }}$ is the sweep period of $10 \mathrm{~ms}$.

When calculating the depth, to complete the transition between TWT and depth, it is necessary to refer to the speed of electromagnetic waves in the ice sheet, which is related to the permittivity and density of firn/ice. Most of the current research uses a constant speed for calculations [JA Uribe et al., 2014]. This paper establishes a wave velocity profile model by estimating the firn/ice density.

According to the basic formula:

$$
C=\frac{C_{0}}{\sqrt{\varepsilon}}
$$

where $C_{0}$ is the velocity of electromagnetic waves in a vacuum; thus, the wave velocity is closely related to the relative dielectric constant of the ice. A Kovacs et al. [1995] presented an empirical formula for the relative dielectric constant $\varepsilon$ :

$$
\varepsilon=(1+0.845 \rho)^{2}
$$

Firn is a mixture of air and ice. With the increased depth, the content of air decreases gradually, which leads to the increasing density of firn. When the density exceeds the critical value $\left(0.83 \mathrm{~g} / \mathrm{cm}^{3}\right)$, firn is converted into ice [Ren et al., 2001]. In this process, the density changes greatly, which has a considerable impact on the velocity of the wave. The detection area of the sounding radar used in this paper includes firn and ice; therefore, the process of densification must be considered. According to the densification model formula proposed by Cuffey et al. [2010], we can calculate the ice layer density $\rho$ at a depth of $z$ :

$$
\rho=\rho_{i}-\left(\rho_{i}-\rho_{s}\right) \exp (-C z)
$$

where $\rho_{i}$ is the density value of pure ice $\left(0.917 \mathrm{~g} / \mathrm{cm}^{3}\right.$ at $\left.-20^{\circ} \mathrm{C}\right)$ and $\rho_{s}$ is the snow density on the surface of the ice sheet. The surface density of ice sheets at ice cores LGB69 and DT263 is $0.39 \mathrm{~g} / \mathrm{cm}^{3}$ [Ren et al., 2001]. The area in Figure 4 is located near DT263, so this value is chosen as the $\rho_{s}$ in this calculation. Minghu et al. [2011] characterized the snow surface density of the East Antarctic from the coast to Dome A. The present study area is consistent with this previous paper, so this value can be corrected according to the geographical position. $C$ is a constant, which is defined as $C=1.9 / z_{t}$, where $z_{t}$ is the critical depth at which firn is converted to ice. Ren et al. [2001] selected four different locations in the area from Zhongshan Station to Dome A spanning approximately $1100 \mathrm{~km}$ and drilled five 50-100 m firn/ice cores at these locations, similar to the area of the present study. According to the density of the five ice cores, the depth at which firn is converted to ice is approximately $60 \mathrm{~m}$; therefore, the value of $z_{t}$ in this paper is $60 \mathrm{~m}$. The parameters in the formula are adjusted according to the local environment, and the accuracy of the calculation result can be improved [Fahnestock et al., 2001]. The correlation between the empirical formula and ice core DT263 regarding the depth-density relationship is 0.94 .

According to Equations (2)-(4), we can derive the functional relationship between the wave velocity and the depth and use it to perform the conversion between TWT and depth. After post-processing of the raw data, the profile shown in Figure 4 was obtained, which shows the lateral variation characteristics within the range of $5 \mathrm{~km}$. 


\section{Wangxiao Yang et al.}

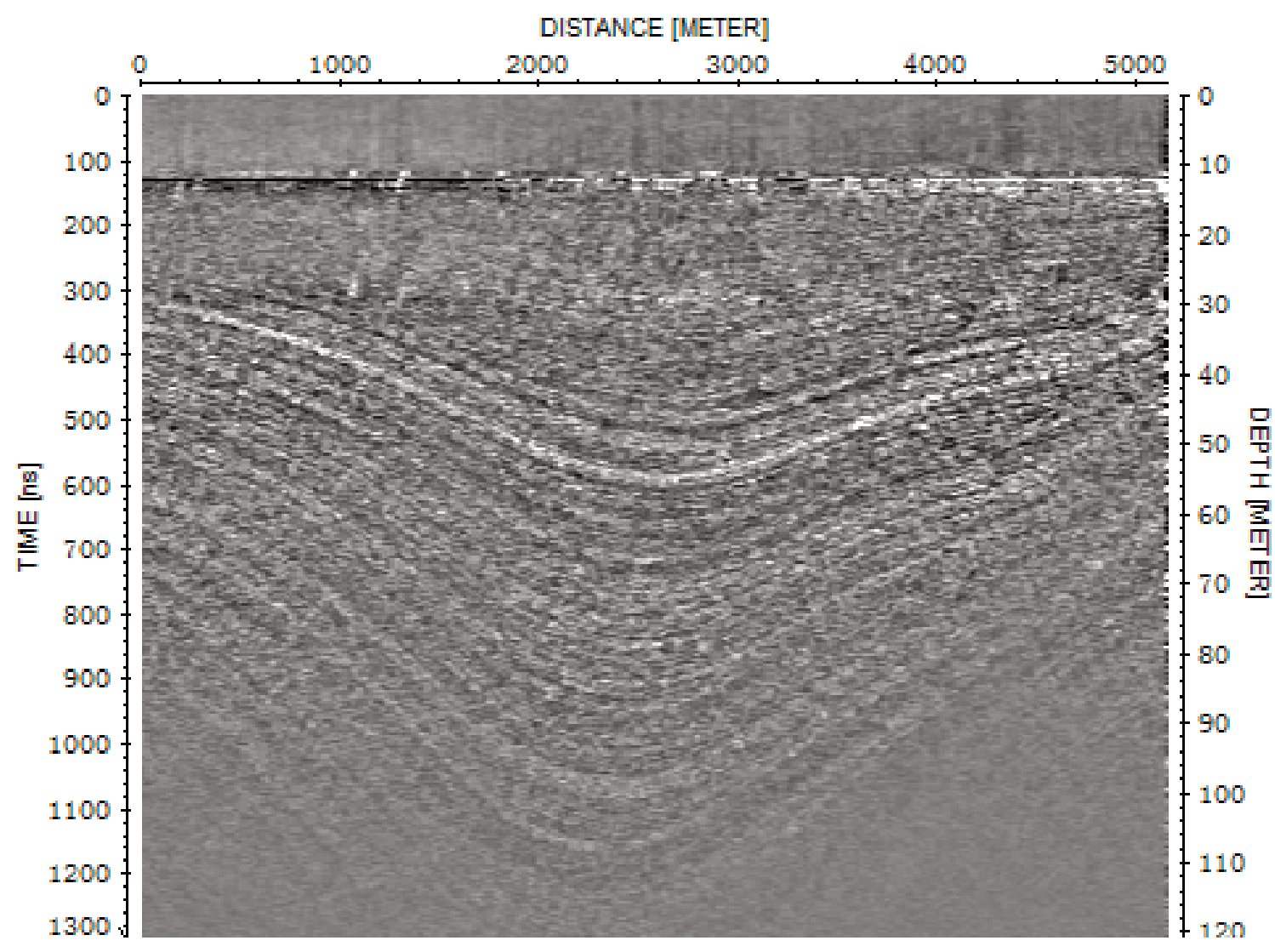

Figure 4. A visualization of the data after application of the curvelet transform

\section{Mapping of isochronous layers}

After signal processing, the information of different layers can be distinguished in the echogram. In this step, we mapped an isochronous layer with a length of $5.8 \mathrm{~km}$ and arbitrarily selected several clearly isochronous layers for tracking and extraction.

In the subsequent accumulation rate study, the accumulation rate model can be used to analyze the effect of depth on the SMB [Das et al., 2015]. In Figure 4, the continuity of the layers is better, and the depth of the layers is characterized by greater depth in the middle of the echogram and relatively shallower on both sides. According to the standard SMB equation,

$$
S M B=z \rho a^{-1}
$$

where $z$ is the depth of the layer, the density $\rho$ of the layer can be calculated according to Equation (4), and $a$ is the age of the layer. The depth of the isochronous layer is proportional to the accumulation rate, so the accumulation rate in the middle of this area is higher. Figure 5 corresponds to the elevation in the echogram. Since the length of this area is only $5.8 \mathrm{~km}$ and the surface altitude change is not severe, the influence of the terrain on the isochronous layer can be observed. We need to analyze the distribution of the layers on a larger scale to determine whether the difference in the rate of accumulation is ubiquitous. And this finding proves that the FMCW sounding radar can help us study the differences in the spatial and temporal distributions of accumulation rate.

By connecting all the cross sections, as shown in Figure 5, the distribution of shallow isochronous layers from Zhongshan Station to Kunlun Station in East Antarctica can be obtained. We chose an echogram of the isochronous layers over a distance of $30 \mathrm{~km}$ in the Lambert Glacier area as an example and selected 5 isochronous layers for tracking and extraction (Figure 6). However, when we added the elevation in an area of $70 \mathrm{~km}$ (Figure 7), the results 
were not satisfactory because the terrain changes usually exceed $200 \mathrm{~m}$ in a large area (more than $100 \mathrm{~km}$ ), whereas the shallow ice sounding radar can measure isochronous layers only within a range of $100 \mathrm{~m}$, and the elevation change far exceeded the depth that FMCW radar can detect. To clearly observe the distribution characteristics of the isochronous layer and calculate the SMB according to the depth (Equation (5)), this article, similar to Robert et al. [1993], employ corresponding elevation information only when analyzing individual regions.

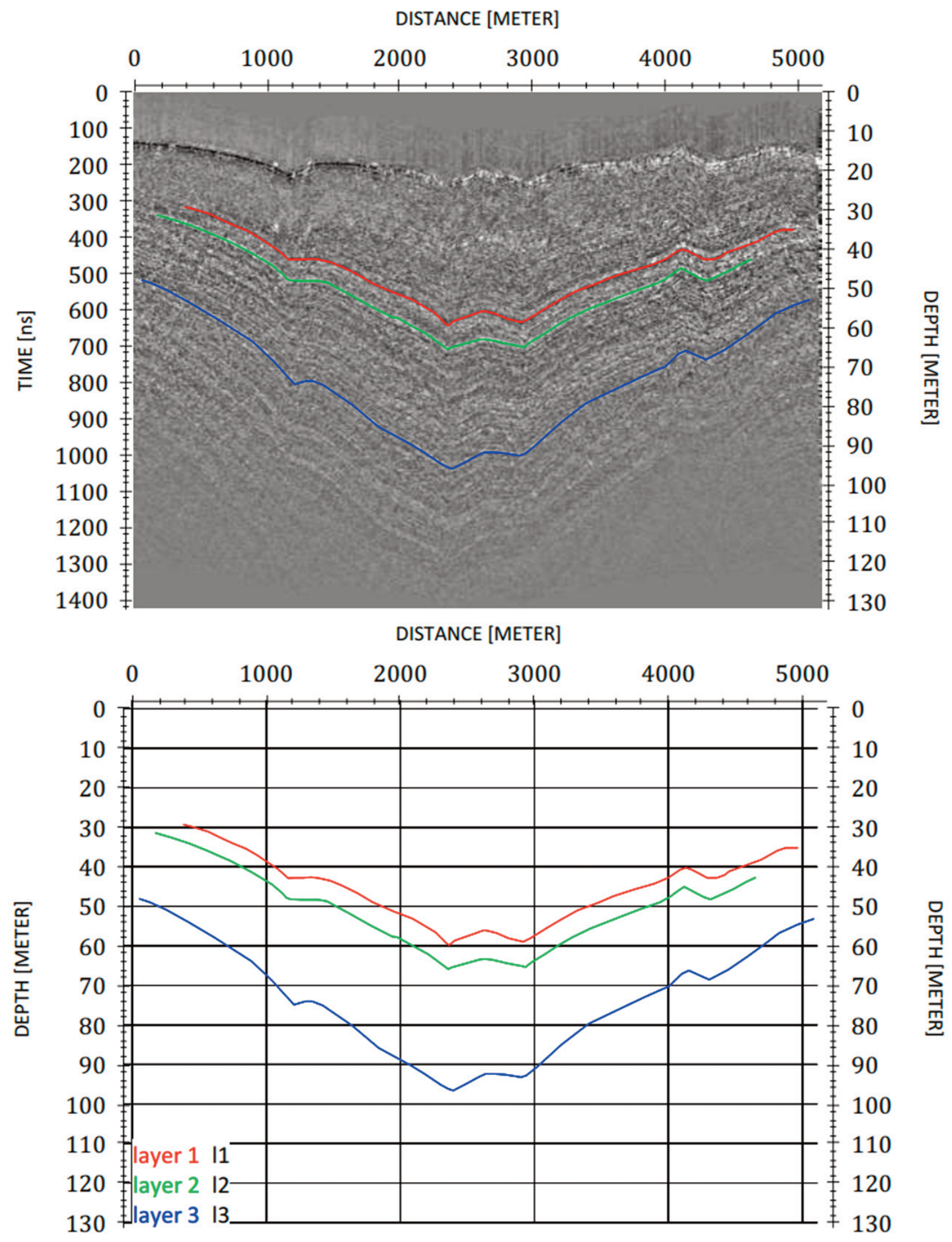

Figure 5. Echogram of the isochronous layers generated after application of the corresponding relative elevations in the data. 


\section{Wangxiao Yang et al.}

\section{Correspondence with ice core data}

To accurately calculate the SMB, the year information recorded in the ice core can be used. Zhou et al. [2006] determined the year in which the isochronous layers were deposited by comparing the trace elements produced by volcanic eruptions with the composition of the ice core. According to the non-sea-salt $\mathrm{SO}_{4}{ }^{2-}$ level, records of at least 17 volcanic eruptions are present in this core. For example, trace elements produced by the eruption of Krakatoa in Indonesia, which occurred in AD1884, appear at a depth of $30.3 \mathrm{~m}$ in the ice core. Thus, layer 1 (Figure 6) represents the location of the ice sheet surface in AD1884, but it is now located at a depth of $30.3 \mathrm{~m}$, which can be interpreted as the mass that has accumulated since AD1884. This accumulation may have been driven by snowfall, wind transport or other factors [Black, et al., 1964].

Thus, the isochronous layer can be defined in terms of its depth at the site where the isochronous layer that formed in AD1884. In addition, the same isochronous layer is understood to have appeared at the same time in other areas, even if the depth of the layer is variable. Such variations in depth arise because the accumulation rates between the regions are different, causing fluctuations in the layers. Similarly, the ice core data show that the eruption of Cosiguina in Nicaragua, which occurred in AD1835, is recorded at a depth of $36.2 \mathrm{~m}$, and the corresponding isochronous layer 2 (Figure 6) can be related to a particular time in the past.

\begin{tabular}{ccccc} 
Volcanic events & D13 & D14 & D15 & D16 \\
Year of eruption (A.D.) & 1285 & Unknown & Unknown & 1259 \\
\hline Time in core (A.D.) & 1286 & 1277 & 1269 & 1260 \\
\hline Depth in core (m) & 72.403 & 73.266 & 74.079 & 75.233 \\
\hline Depth of volcanic record (m) & 74.173 & 75.035 & 75.848 & 77.002 \\
\hline TWT in RES (ns) & 745.9 & 757.9 & 770.8 & 778.2 \\
\hline Depth in RES (m) & 70.06 & 70.97 & 72.20 & 72.90 \\
\hline Relative error & $5.5 \%$ & $5.41 \%$ & $4.81 \%$ & $5.3 \%$ \\
\hline
\end{tabular}

Table 1. Comparison of radar data with volcanic eruption records using ice core DT263.

According to the above principle, accurate year-depth information can be obtained. However, radar data often contain certain deviation; the main reason for this error is that the variation of the propagation velocity of electromagnetic waves in firn/ice exhibits a nonlinear characteristic. As the depth increases, the propagation velocity error of electromagnetic waves in firn/ice also increases.

We measured the area where ice core DT263 was located on December 24, 2015 [Drews et al., 2009], but the ice core had been drilled by the inland team in AD1999, during which snowfall increased the depth of the volcanic records contained in the ice core. According to the SMB data from stakes observation, the average accumulation rate in the region $860 \mathrm{~km}$ from the coast from AD1999 to AD2015 was $55.35 \mathrm{~kg} / \mathrm{m}^{2} / \mathrm{a}^{1}$ and exhibited no temporal changes [Ding et al., 2011]. The thickness of the snow added in this area was estimated to be $1.76 \mathrm{~m}$.

In Figure 6a, layer 4 is selected to perform error analysis on the wave velocity model. Four unknown volcanic eruption records were found at depths of $72.403 \mathrm{~m}, 73.266 \mathrm{~m}, 74.079 \mathrm{~m}$, and $75.233 \mathrm{~m}$ of ice core DT263 [Li et al., 2009]. Together with the increased snow thickness during AD1999-2015, radar data can be calibrated based on these volcanic records. Four closely visible radar reflection layers can be found in the TWT range of 740-780 ns (Figure 6b). The parameters of these four isochronous layers are shown in Table 1, which shows that the relative error between the depth of D13-D16 and the volcanic record in the ice core is approximately $5 \%$, which is consistent with the findings of Frezzotti et al. [2005]. 
(a)
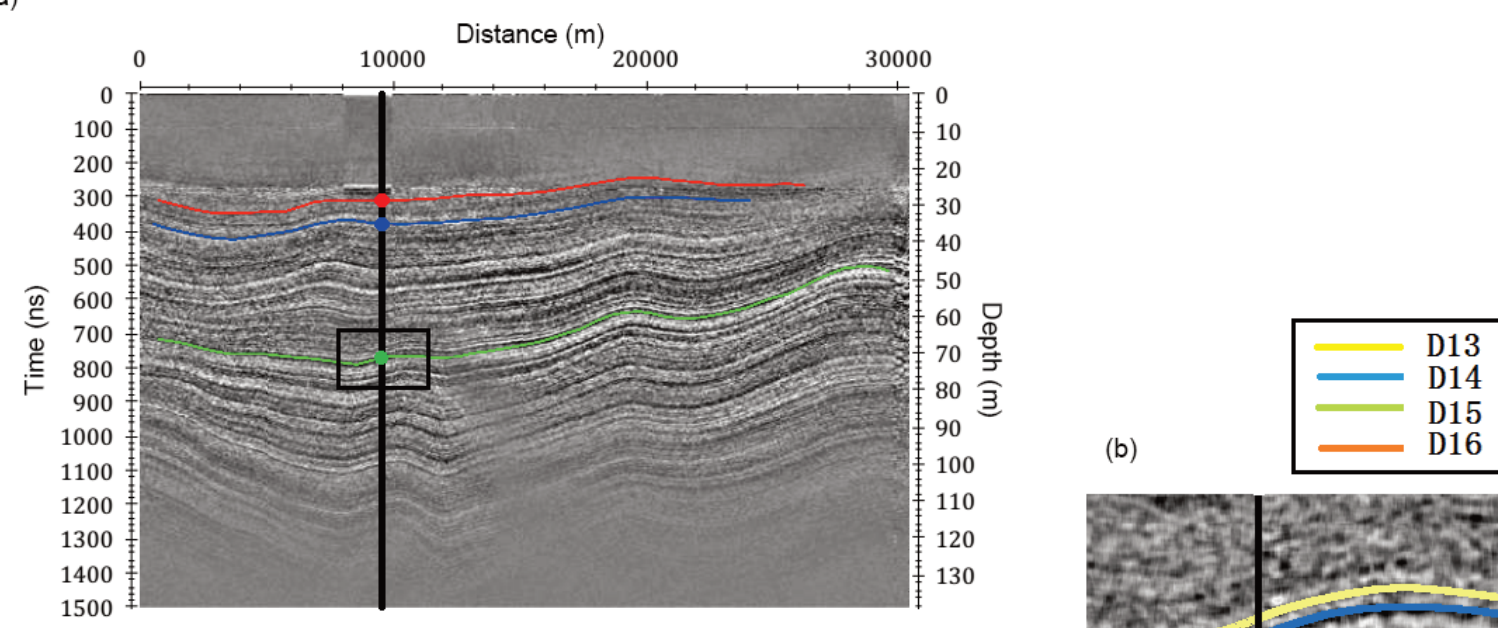

(c)
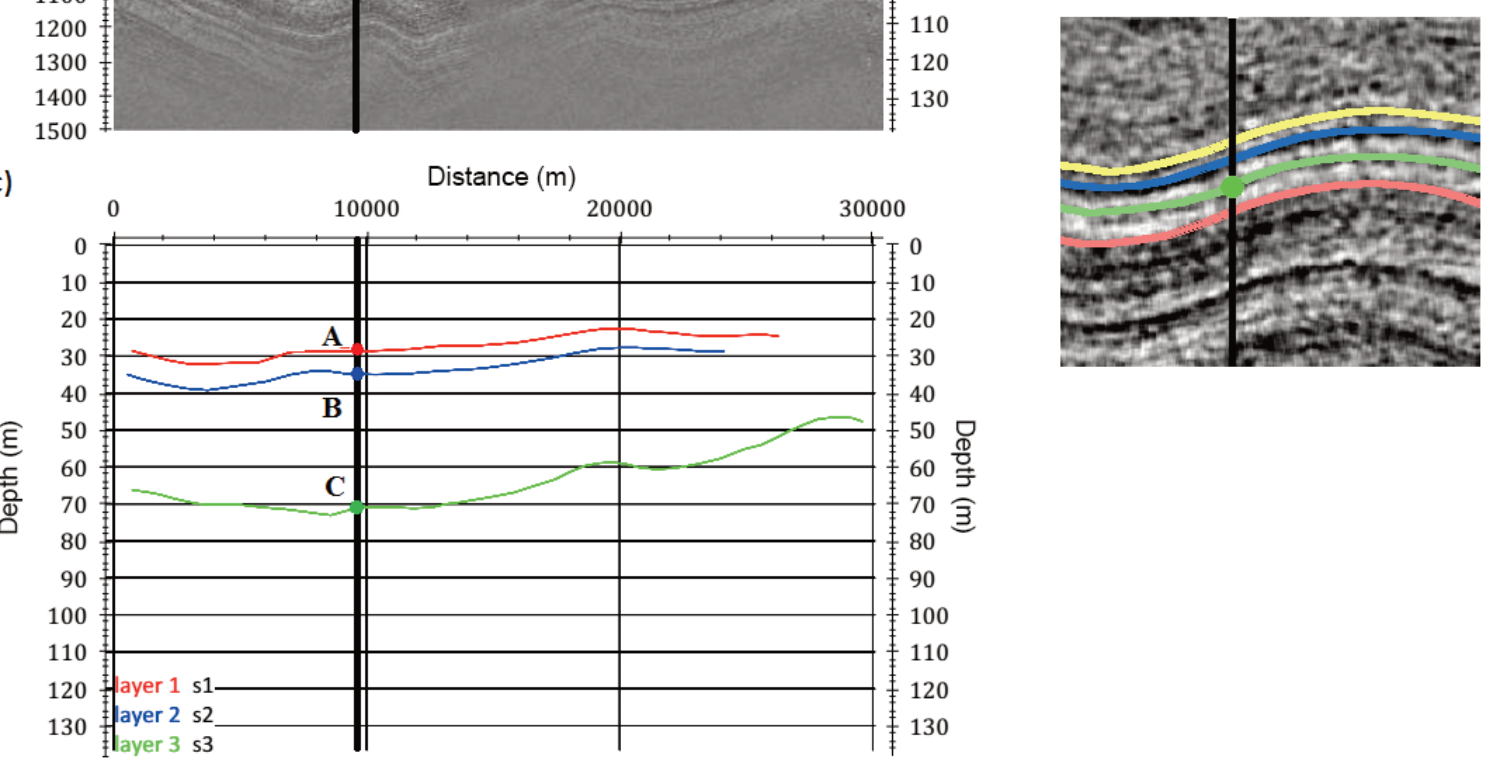

Figure 6. Radar data in the range of $30 \mathrm{~km}$ near ice core DT263. (a) Echogram obtained by signal processing and drawing isochronous layers; the black line shows the location of ice core DT263; the red point A shows the trace of the Krakatoa eruption in Indonesia in AD1884, with a depth of $30.3 \mathrm{~m}$; the blue point B shows the traces of the Cosiguina volcano eruption that occurred in Nicaragua in AD1835, with a depth of $36.188 \mathrm{~m}$; the green point $\mathrm{C}$ shows an unknown volcanic record from AD1285, with a depth of $72.403 \mathrm{~m}$. A partial cross-sectional view near the yellow point $\mathrm{C}$ (the black box) is enlarged to obtain (b), where the four lines represent four adjacent high-density isochronous layers in Table 1. (c) Extraction of three isochronous layers drawn in (a).

The difference between the two data sets is due in part to the increased snow thickness error within AD1999-2015. The firn formed during this period has not yet reached the critical density $\left(0.55 \mathrm{~g} / \mathrm{cm}^{3}\right)$, and the process of snow densification is obvious in this range [Herron et al., 1980]. Therefore, the present paper has a certain degree of overestimation of the inversion results. In addition, although Equation (4) is an often useful empirical formula for the depth-density relationship and has a high correlation with the measured data of DT263, it still contains the errors.

However, when using a constant wave velocity of $0.168 \mathrm{~m} / \mathrm{ns}$ (the electromagnetic wave velocity in pure ice), the relative error reached $15.5 \%$, which shows that the velocity model used in this paper has higher precision when calculating depth. If the model is used in a deeper range, it will exhibit greater advantages, which provides a foundation for accurate calculations of accumulation rate.

The depth of internal reflection horizons can be calibrated by the corresponding ice core, and the depth-year information in the vicinity of the ice core can also be determined. As shown in Figure 7, the isochronous layer in the region is extended, and continuous isochronous layers within a few hundred kilometers can be obtained so that the SMB can be studied on a larger scale. This method can also be used to plot the three-dimensional distribution of a particular isochronous layer after multiple investigations [Siegert et al., 2010]. 


\section{Wangxiao Yang et al.}

\section{Presentation of isochronous layers over large areas}

At the end of this paper, a number of typical areas are also analyzed, including the Dome A area, a region 100 $\mathrm{km}$ away from Dome A [Sun et al., 2009], and the region surrounding the Lambert Glacier, which is the largest glacier in the world. These regions present a wide range of layers.

In Figure 7, the randomly selected images of different depths and layers in these regions show the shallow ice structure and the depth variation in the horizontal direction within $\sim 130 \mathrm{~m}$. The depth information of the isochronous layers is shown in Figure 7. Therefore, we can, as in the Section 5, track and map specific isochronous layers using the ice core data and determine the ages corresponding to specific depths.

The isochronous layers of Dome A and the Lambert Glacier are continuous and can be traced over large areas. Analysis of the isochronous layers in these regions shows that the elevation changes are relatively small in the Dome A, and the structure of the shallow isochronous layers also shows excellent stability. The Lambert Glacier area displays relatively stable elevations; however, the isochronous layers are more volatile, although they are still relatively continuous, and the layers are folded in local areas.

Through analysis of the relief (depth variation) of the isochronous layers shown in Figure 7 (a) and (b), the maximum depth, the minimum depth, the average depth and the standard deviation of the layers are obtained (Table 2, Table 3). The standard deviation of the isochronous layers' depth within the Lambert Glacier region is more than 3 times that of the Dome A. This result shows that the isochronous layers are relatively flat in the Dome A, whereas the changes in the Lambert Glacier are more pronounced.

\begin{tabular}{ccccc} 
Layer & Layer 1 & Layer 2 & Layer 3 & Layer 4 \\
\hline Minimum depth (m) & 22.7 & 31.0 & 38.8 & 51.5 \\
\hline Maximum depth (m) & 41.6 & 54.5 & 69.0 & 90.6 \\
\hline Average depth (m) & 33.1 & 43.0 & 54.9 & 70.8 \\
\hline Standard deviation (m) & 3.4 & 4.4 & 5.6 & 9.4 \\
\hline
\end{tabular}

Table 2. Information on the depth of layers in the Dome A.

\begin{tabular}{cccc} 
Layers & Layer 1 & Layer 2 & Layer 3 \\
Minimum depth (m) & 39.3 & 51.6 & 56.9 \\
\hline Maximum depth (m) & 67.1 & 86.1 & 94.9 \\
\hline Average depth (m) & 46.6 & 57.6 & 64.1 \\
\hline Standard deviation (m) & 12.5 & 14.8 & 16.4 \\
\hline
\end{tabular}

Table 3. Information on the depths of layers on the Great Icefield of the Lambert Glacier 
Infer Isochronous Layer from FMCW Radar
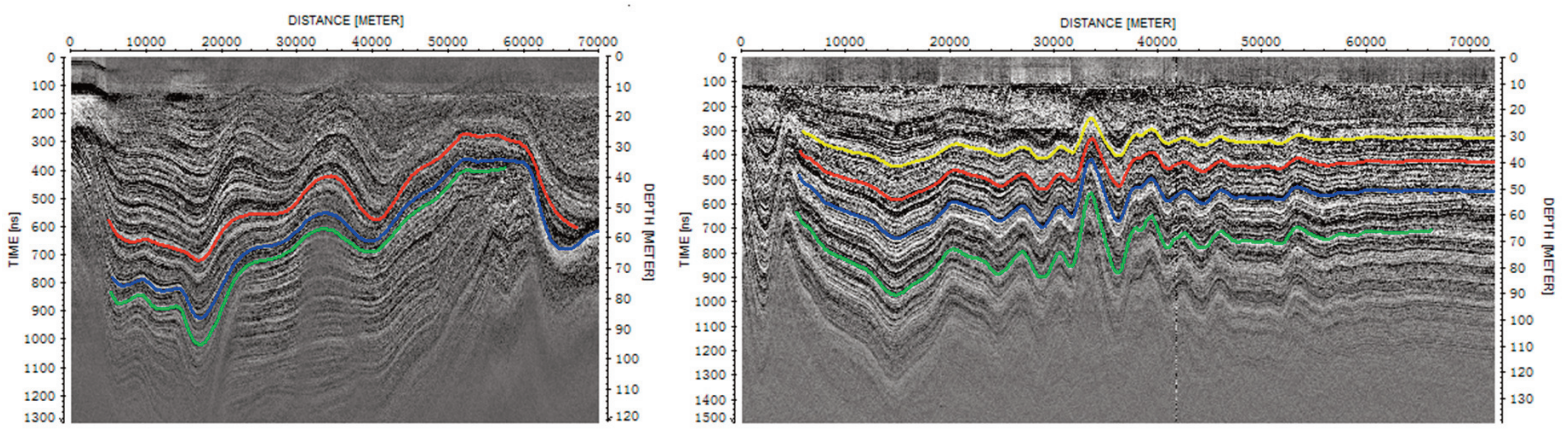

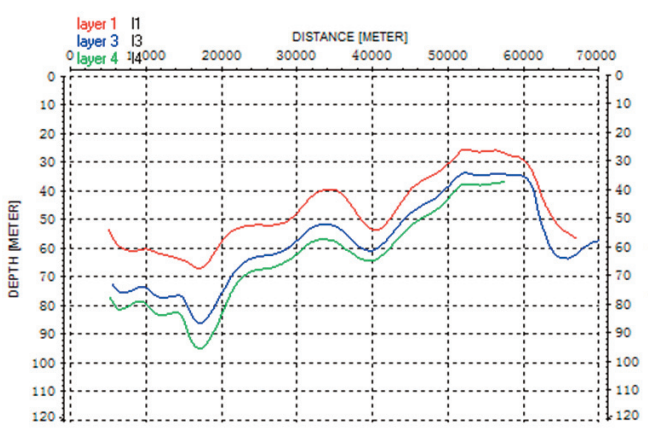

(a)

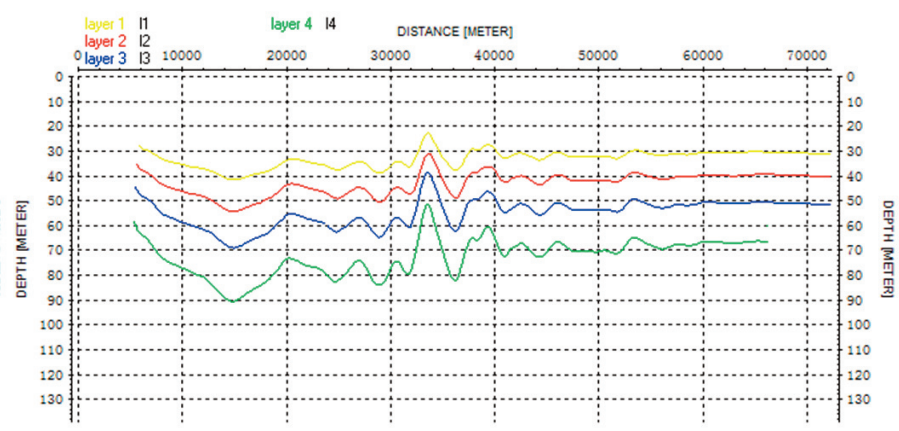

(b)

Figure 7. Presentation of the isochronous layers over large-scale areas; (a) a display of the Great Icefield of the Lambert Glacier; (b) a display of the Dome A.

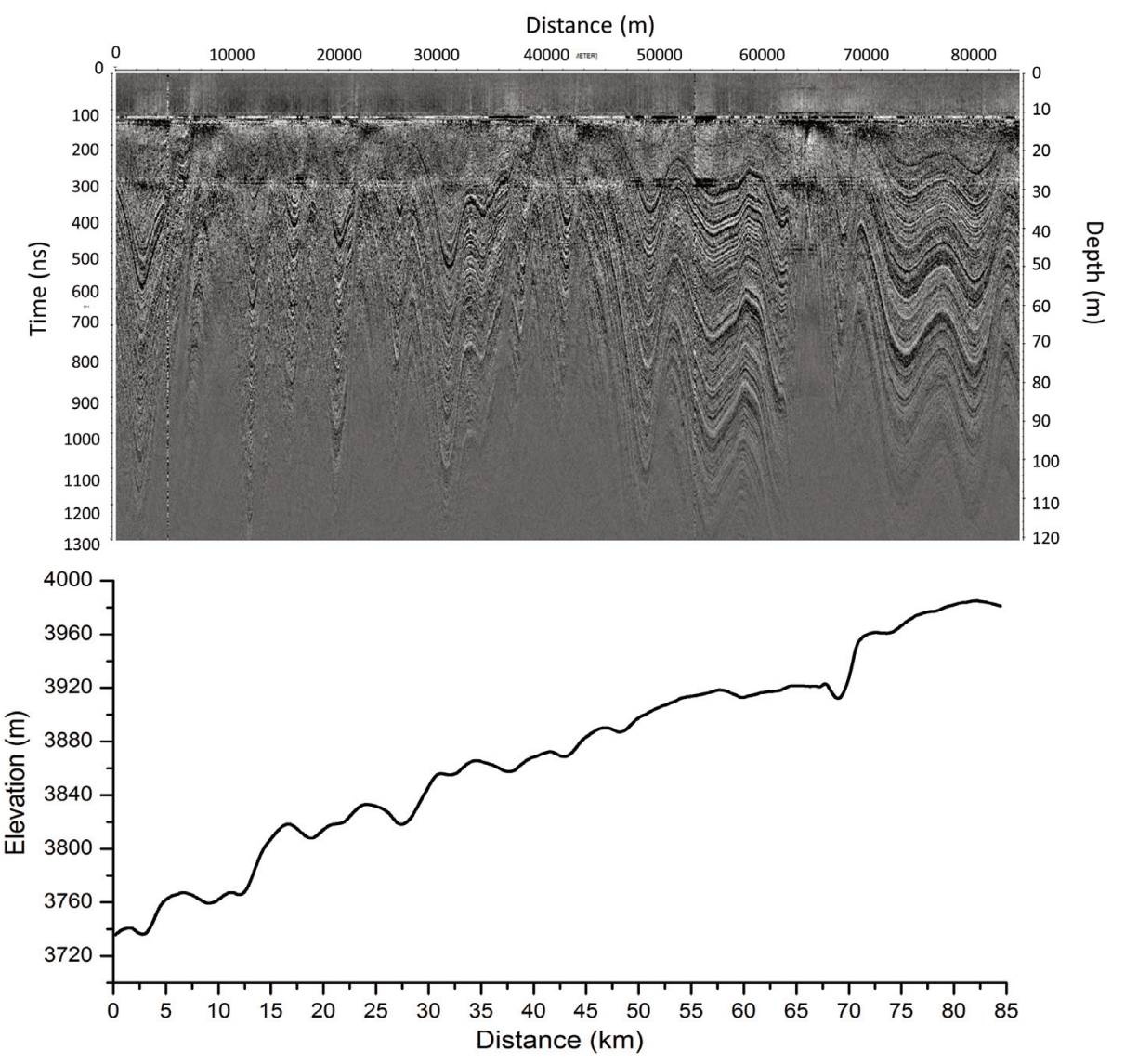

Figure 8. A display of the area $100 \mathrm{~km}$ from Dome A and the corresponding elevation. The location at which the layers are folded is often accompanied by dramatic changes in elevation. 


\section{Wangxiao Yang et al.}

In addition, the sharply shrinking layer (contraction zone) cannot be tracked. It can be found that in the area around Dome A, where the detection length is $84 \mathrm{~km}$, we cannot effectively trace the distribution of the isochronous layers due to the large number of shrinkage areas. In the area where Profile 3 (Figure 1) is located, the elevation increases more rapidly, and a phenomenon in which multiple isochronous layers converge is frequently observed, thus impeding the continuity of the isochronous layers.

However, during the extraction process, a sharper slope along the internal layer (the area shown in Figure 8 and Profile 3 in Figure 1) was produced. Since the layers are compressed, making it impossible to clearly distinguish the periods of the layers and affect the calculation of the depth-year relationship [Legarsky and Gao, 2006].

The shrinkage of the layer will be concentrated in certain areas, and there are many explanations for the appearance of this phenomenon. For example, after the ice flows into different regions, the tributary and the main stream are concentrated by the lateral compression of the mechanical anisotropic ice [Bons et al., 2016]; the fold produced by the ice flowing through the basal topography of the onset region is preserved [King, 2011]. It is also possible that the interaction of topography, altitude and the wind field impact the accumulation rate [Fujita et al., 2011].

Analysis of all radar data showed that this shrinkage phenomenon occurs along the coast and in individual inland areas. The folding of the layer appears multiple times on the $80 \mathrm{~km}$ scale, as shown in Figure 8. According to the data reported by Shengkai et al. [2008], the ice flow velocity in the Profile 3 region gradually increases, and the flow direction substantially matches the surface elevation profile; therefore, it is likely to represent local layer mixing and compression caused by the ice flow. The surface topography of Profile 3 is very complex and has high spatial variability [Minghu et al., 2011]. Wind-driven processes also have a great influence on the distribution of accumulation rate.

After analyzing these three regions, it can be found that the distribution of isochronous layers differs among regions. These phenomena are closely related to the spatial transformation of the accumulation rate. Therefore, further analyses can be conducted using geographic and meteorological factors.

\section{Conclusion}

This paper mainly describes the shallow exploration radar observation work conducted by CHINARE 32 from Zhongshan Station to Kunlun Station in 2015. The process of collecting data for the entire section is described, detailed processing was then carried out, the isochronous layers were drawn, and the correspondence of the results with the ice core was demonstrated. The results are summarized below.

1) FMCW sounding radar is a high-resolution radar system. After signal processing, a clear echogram of the isochronous layers can be obtained. And layers within $\sim 100 \mathrm{~m}$ can be distinguished and extracted.

2) To calculate the SMB by isochronous layer, the depth of each layer needs to be accurately calibrated, but the density of the firn/ice changes significantly, resulting in a large change in the velocity of the electromagnetic waves in the shallow region. Therefore, according to the empirical formula, the velocity model of electromagnetic waves in firn/ice was established to calculate the depth of the layer. Based on the volcanic records stored in ice core DT263, the error analysis and calibration of the depth showed the superiority of the model results.

3) During the entire exploration transect, the elevation changes by more than $4000 \mathrm{~m}$; therefore, the elevation of the transect cannot be ignored. However, the elevation can only be matched in a small range. When the elevation change is much greater than the detection depth, it is difficult to observe the distribution of shallow isochronous layers.

4) Isochronous layers of different depths sometimes converge and can still be tracked in constricted areas. This folding phenomenon occurs along the coast and in individual inland areas, and many explanations exist for the appearance of this phenomenon. However, an analysis of radar operations indicates that the constricted regions are not a result of radar instability [Ilisei and Bruzzone, 2014]. This phenomenon is probably due to the folding and mixing of different layers caused by ice flow movement and wind-driven processes.

5) As seen from Table 2 and Table 3, there is a difference in the standard deviations of the layer depth in the Dome A and the Lambert Glacier. However, the isochronous layers cannot even be effectively extracted in the region $100 \mathrm{~km}$ away from Dome A. It can be found that the distribution of isochronous layers differs among regions. Meanwhile, it can be speculated that among these regions, the accumulation rates differ strongly, and the reasons for these phenomena deserve additional analysis [Wang and Sun, 2016]. 
Acknowledgements. This work was supported by the National Natural Science Foundation of China (41776199) and was carried out during the $32^{\text {nd }}$ China Antarctic Scientific Expedition. Thanks to Yuzhong ZHANG and Xueyuan TANG for providing us with the radar principle and data processing help. Taiyuan University of Technology and the Polar Research Institute of China provided logistical support.

\section{References}

Bakwad K.M., S. S. Pattnaik, B. S. Sohi, S. Devi, B. K. Panigrahi and S.V. Gollapudi (2009). Bacterial foraging optimization technique cascaded with adaptive filter to enhance peak signal to noise ratio from single image. IETE J. Res. 55(4), 173-179.

Bao Q.Z., Q.C. Li and W.C. Chen (2014). GPR data noise attenuation on the curvelet transform. Appl. Geophys. 11(3), 301-310.

Black H.P., W. Budd (1964). Accumulation in the region of Wilkes, Wilkes Land, Antarctica. J. Glaciol. 5(37), 3-15.

Bo S., M.J. Siegert, S. M. Mudd, D. Sugden, S. Fujita, C. Xiangbin (2009). The Gamburtsev mountains and the origin and early evolution of the Antarctic Ice Sheet, Nature 459 (7247), 690-693.

Bons P.D., D. Jansen, F. Mundel, C.C. Bauer, T. Binder,O. Eisen, M.W. Jessell, M. G. Llorens, F. Steinbach, D. Steinhage and I. Weikusat (2016). Converging flow and anisotropy cause large-scale folding in Greenland's ice sheet, Nat. Commun. 7, 11427.

Conway H., T. A. Neumann, S. Price, E. D. Waddington, D. Morse, K.Taylor, P. A. Mayewski, D. Dixon, E. Pettit, and E. J. Steig (2005). Proposed drill site near the Ross-Amundsen ice divide, West Antarctica, White paper for the US Ice Core Working Group. http:// www.waisdivide.unh.edu/Reference/Download.pm/761/Document

Cuffey K.M., W.S.B. Paterson (2010). The physics of glaciers. Academic Press.

Ren J., D. Qin, C. Xiao (2001). Preliminary results of the inland expeditions along a transect from the Zhongshan Station to Dome A, East Antarctica. J. Glaciol. Geocryol, 23(1), 51-56.

Cui X., B. Sun and G.Tian (2009). Progress and Prospect of Ice Radar in Investigating and Researching Antarctic Ice Sheet, Adv. Earth Sci. 24 (4), 392-402.

Das I., T.A. Scambos, L. S. Koenig, M. R Broeke, J. Lenaerts (2015). Extreme wind-ice interaction over Recovery Ice Stream, East Antarctica. Geophys. Res. Lett. 42(19), 8064-8071.

Drewry D.J. (1975). Comparison of Electromagnetic and Seismic-Gravity Ice Thickness Measurements in East Antarctica, J. Glaciol. 15 (73), 137-150.

Drews R., O. Eisen, I. Weikusat (2009). Layer disturbances and the radio-echo free zone in ice sheets, The Cryosphere, 3 (2), 195-203.

Fahnestock M., W. Abdalati, S. Luo, S. Gogineni (2001). Internal layer tracing and age-depth-accumulation relationships for the northern Greenland ice sheet. J. Geophys. Res. Atm.106(D24), 33789-33797.

Frezzotti M., M. Pourchet, O. Flora, S. Gandolfi, M. Gay, S. Urbini and M. Severi (2005). Spatial and temporal variability of snow accumulation in East Antarctica from traverse data. J. Glaciol. 51 (172), 113-124.

Fujita S., H. Maeno, S. Uratsuka, T. Furukawa, S. Mae (1999). Nature of Radio Echo Layering in the Antarctic Ice Sheet Detected by a Two-Frequency Experiment, J. Geophys. Res. Sol. Earth 104 (B6), 13013-13024.

Fujita S., P. Holmlund, I. Andersso I. Brown, H. Enomoto, Y. Fujii, K. Fujita, K. Fukui, T. Furukawa, M. Hansson, K. Hara, Y. Hoshina, M. Igarashi, Y. Iizuka, S. Imura, S. Ingvander, T. Karlin, H. Motoyama, F. Nakazawa, H. Oerter, L. E. Sjöberg, S. Sugiyama, S. Surdyk, J. Strö, R. Uemura and F. Wilhelms (2011). Spatial and temporal variability of snow accumulation rate on the East Antarctic ice divide between Dome Fuji and EPICA DML, The Cryosphere, 5 (4), 1057-1081.

Galin N., A. Worby, T. Markus, C. Leuschen and P. Gogineni (2012). Validation of Airborne FMCW Radar Measurements of Snow Thickness Over Sea Ice in Antarctica, IEEE Trans. Geosci. Remote Sens. 50 (1), 3-12.

Gogineni S., D. Braaten, C. Allen, J. Paden, T. Akins, P. Kanagaratnam, K. Jezek, G. Prescott, G. Jayaraman, V. Ramasami, C. Lewis, and D. Dunson (2007), Polar Radar for Ice Sheet Measurements (PRISM), Remote Sens. Environ. 111 (2-3), 204-211; doi:10.1016/j.rse.2007.01.022.

Gogineni S., T. Chuah, C. Allen, K. Jezek and R. K. Moore (1998). Instruments and Methods an Improved Coherent Radar Depth Sounder, J. Glaciol. 44 (148), 659-669.

Herron M.M., C.C. Langway (1980). Firn densification: an empirical model. J. Glaciol. 25(93): 373-385. 


\section{Wangxiao Yang et al.}

Ilisei A.M. and L. Bruzzone (2014). A Model-Based Technique for the Automatic Detection of Earth Continental Ice Subsurface Targets in Radar Sounder Data, IEEE Geosci. Remote Sens. Lett. 11 (11), 1911-1915

King E. (2011). Ice stream or not? Radio-echo sounding of Carlson Inlet, West Antarctica, The Cryosphere, 5(4), 907916.

Kovacs A., A.J. Gow, R.M. Morey (1995). The in-situ dielectric constant of polar firn revisited. Cold Reg. Sci. Technol. 23(3), 245-256.

Lang S. X. Liu, B. Zhao, X. Chen, G. Fang (2015a). Focused synthetic aperture radar processing of ice-sounding data collected over the east antarctic ice sheet via the modified range migration algorithm using curvelets. IEEE Trans. Geosci. Remote Sens. 53(8), 4496-4509.

Lang S., B. Zhao, X. Liu, G. Fang (2015b). Two-dimensional imaging of ice sheets of airborne radar sounder via a combined modified range migration algorithm based on ISFT and beamforming using curvelets. IEEE J. Sel. Top. Appl. Earth Obs. Rem. Sens., 8(1), 76-89.

Laird C.M., W.A. Blake, K. Matsuoka, H. Conway, C.T. Allen (2010). Deep Ice Stratigraphy and Basal Conditions in Central West Antarctica Revealed by Coherent Radar, IEEE Geosci. Remote Sens. Lett. 7 (2), 246-250.

Legarsky J.J. and X. Gao (2006). Internal Layer Tracing and Age-Depth Relationship From the Ice Divide Toward Jakobshavn, Greenland, IEEE Geosci. Remote Sens. Lett. 3 (4), 471-475.

Le Meur E., O. Magand, L. Arnaud, M. Fily, M. Frezzotti, M. Cavitte, S. Urbini (2018). Spatial and temporal distributions of surface mass balance between Concordia and Vostok stations, Antarctica, from combined radar and ice core data: first results and detailed error analysis. The Cryosphere., 12, 1831-1850, doi:https://doi.org/10.5194/tc-12-1831-2018

Leuschen C., R. Hale, S. Keshmiri, J.B. Yan (2014). UAS-Based Radar Sounding of the Polar Ice Sheets, IEEE Geosci. Remote Sens. Magazine 2 (1), 8-17.

Li Y., J. Cole-Dai, L. Zhou (2009). Glaciochemical evidence in an East Antarctica ice core of a recent (AD 1450-1850) neoglacial episode. J. Geophy. Res. Atm. 114(D8), 1-11.

Macheret Y.Y. and A. B. Zhuravlev (1982). Radio Echo-Sounding of Svalbard Glaciers, J. Glaciol. 28 (99), 295-314.

Mayewski P.A., M. Frezzotti, N. Bertler, T. Van Ommen, G. Hamilton, T. H.Jacka, Brian Welch (2005). The International Trans-Antarctic Scientific Expedition (ITASE): An Overview, Ann. Glaciol. 41 (1),180-185.

Minghu D., X. Cunde, L.Yuansheng, R. Jiawen, H. Shugui, J. Bo, S. Bo (2011).Spatial variability of surface mass balance along a traverse route from Zhongshan station to Dome A, Antarctica, J. Glaciol. 57(204), 658-666.

Paren J.G. and G. de. Q. Robin (1975). Internal Reflections in Polar Ice Sheets, J. Glaciol. 14 (71), 251-259.

Petit J.R., M. Briat, A. Royer (1981). Ice Age Aerosol Content from East Antarctic Ice Core Sample and Past Wind Strength, Nature 293 (5831), 391-394.

Robert W.J., M.G. Anthony, L.G. David, M.H. Steven, L.W. David (1993). Interpretation of radar-detected internal layer folding in West Antarctic ice streams. J. Glaciol. 39 (133), 528-537.

Shengkai Z., E. Dongchen, W. Zemin, L. Yuansheng, J. Bo, Z. Chunxia (2008). Ice velocity from static GPS observations along the transect from Zhongshan station to Dome A, East Antarctica, Ann. Glaciol. 48, 113-118.

ShuGui H., L. YuanSheng, X. CunDe, R. JiaWen (2007). Recent Accumulation Rate at Dome A, Antarctica, Chinese Sci. Bull. 52, (3), 428-431

Siegert M J. (1999). On the Origin, Nature and Uses of Antarctic Ice-sheet Radio-Echo Layering, Prog. Phys. Geog. 23 (2), 159-179.

Siegert M.J., M. Pokar, J.A. Dowdeswel, T. Benham (2010). Radio-echo layering in West Antarctica: a spreadsheet dataset. Earth Surface Processes and Landform 30 (12), 1583-1591.

Stove A.G. (1992). Linear FMCW Radar Techniques, IEEE Proceedings F - Radar and Signal Processing, 139 (5), $343-$ 350.

Urbini S., A Zirizzotti, J.A. Baskaradas, I.E. Tabacco, L. Cafarella (2017). Airborne radio echo sounding (RES) measures on alpine glaciers to evaluate ice thickness and bedrock geometry: Preliminary results from pilot tests performed in the ortles-cevedale group (Italian alps), Ann. Geophys. 60 (2).

Urbini S., L. Cafarella, A. Zirizzotti, I.E. Tabacco (2010). Radio echo sounding data analysis of the Shackleton Ice Shelf, Annals of Geophysics, 53 (2), 79-87.

Uribe J.A., R. Zamora, G. Gacitúa, A. Rivera, D. Ulloa (2014). A low power consumption radar system for measuring ice thickness and snow/firn accumulation in Antarctica. Ann. Glaciol. 55(67), 39-48.

Uslu E. and S. Albayrak (2014). Curvelet-based synthetic aperture radar image classification. IEEE Geosci. Remote 


\section{Infer Isochronous Layer from FMCW Radar}

Sens. Lett. 11(6), 1071-1075.

Vaughan D.G., H.F.J. Corr, C.S.M. Doake, E.D. Waddington (1999). Distortion of Isochronous Layers in Ice Revealed by Ground-Penetrating radar, Nature, 398 (6725), 323-326.

Wang T.T. and B. Sun (2016). Spatio-temporal variability of past accumulation rates inferred from isochronous layers at Dome A, East Antarctica, Ann. glacial. 57 (73), 87-93.

Winter A., D. Steinhage, E. J. Arnold, D. D. Blankenship, M. G Cavitte, H. F. Corr and O. Eisen (2017). Comparison of measurements from different radio-echo sounding systems and synchronization with the ice core at Dome C, Antarctica, The Cryosphere 11(1), 653-668.

Xiao C., M. Ding, V. Masson-Delmotte, R. Zhang, B. Jin, J. Ren (2013). Stable Isotopes in Surface Snow Along a Traverse Route from Zhongshan Station to Dome A, East Antarctica, Climate Dynam., 41 (9-10), 2427-2438.

Zhou L., Y. Li, C.D. Jihong, D. Tan, B. Sun, J. Ren, L. Wei, H. Wang (2006). A 780-year record of explosive volcanism from dt263 ice core in east antarctica. Chinese Sci. Bull. 51(22), 2771-2780.

"CORRESPONDING AUTHOR: Yinke DOU,

Taiyuan University of Technology, Electrical and Power Engineering,

Taiyuan, China;

e-mail: douyk8888cn@126.com

(c) 2020 the Istituto Nazionale di Geofisica e Vulcanologia.

All rights reserved 